\title{
Return to work after spinal cord injury
}

\author{
PCD Tomassen ${ }^{1}$, MWM Post ${ }^{1}$ and FWA van Asbeck*,1 \\ ${ }^{1}$ Rehabilitation Centre "De Hoogstraat", Rembrandtkade 10, 3583 TM Utrecht, The Netherlands
}

Objective: To describe predictors of return to work after spinal cord injury (SCI), in particular the physical intensity of the pre-injury job.

Study design: Survey.

Setting: Patients' home.

Methods: We interviewed 234 persons with a spinal cord injury (SCI) between 18 and 65 years of age and who were gainfully employed at the time of the injury. Possible predictors were tested with logistic regression analyses.

Results: After the SCI, only $37 \%$ of the persons were gainfully employed. People with heavy and strenuous physical work pre-injury regained work in only $25 \%$, respectively $21 \%$. Being male (Odds Ratio (OR) 3.70), light to moderate physical job pre-injury (OR 3.16), high Barthel Index (OR 2.76), high educational level (OR 2.12) and education post-injury (OR 2.14) were significant predictors for returning to gainful work after injury. Many unemployed persons thought they were capable of working.

Conclusions: Only a minority returned to gainful employment after SCI even to a physically less demanding job. In addition to intensive inpatient re-education, long-term support in job seeking is very important, including switching to a less demanding job.

Spinal Cord (2000) 38, 51-55

Keywords: spinal cord injury; employment; vocational; rehabilitation

\section{Introduction}

One of the most important goals of any rehabilitation program is return to gainful employment. Compared with non-disabled persons, persons with paraplegia were more likely to consider work as a source of personal fulfilment and social recognition. In addition, persons with paraplegia are less likely to positively value the fact of non-working. ${ }^{1}$ Furthermore a positive correlation between activity, both social and vocational, and survival after SCI was found. ${ }^{2}$

Employment rates after SCI ranged from $13 \%$ to $51 \%{ }^{3-13}$ For subjects with a follow up period of less than 5 years post injury, the average reported returnto-work rate was $38 \%{ }^{4}$

Several predictive factors influencing the return to gainful employment have been identified. Educational history was found to be one of the most important positive predictive factor for employment after SCI. ${ }^{5-11,14}$ In addition, younger age, younger age at injury and time since injury were found to be correlated with employment status. ${ }^{7-14}$ Completeness of injury, ${ }^{8}$ gender, impairment type, study since injury, ${ }^{10}$ motivation to work, ${ }^{4,6}$ social support, and the ability to drive a $\operatorname{car}^{6}$ have also been described as predictive factors. In contrast, level of SCI does not

*Correspondence: FWA van Asbeck appear to be an important predictor for re-employment. $^{5,7}$

To our knowledge, thus far no studies have investigated the relationship between the physical strain of a pre-injury occupation and the employment status after SCI. It is conceivable that it is easier to return to gainful employment in less physically demanding jobs or in jobs that mainly require cognitive capacities than in jobs that mainly demand strenuous efforts. One study found that prior to the SCI, occupations ranged throughout all employment categories, while post-injury a shift was found toward the administration, clerical and finance categories. ${ }^{15}$

The purpose of this study was twofold. First we investigated which factors can positively predict return to gainful employment after SCI. Second, we investigated whether the return to gainful employment is influenced by the physical intensity of the preinjury job.

\section{Methods}

\section{Respondents}

This study is part of a larger research project on quality of life and service delivery after SCI in the Netherlands. Persons with SCI between the ages of 18 
and 65 years who were gainfully employed at the time of the injury and who were living independently postinjury were asked to participate. All persons underwent a rehabilitation program in a specialised rehabilitation centre between 1986 and 1992. Persons with lesions due to malignant tumour and those who were completely recovered were excluded. The respondents were interviewed at home.

\section{Instruments}

Demographic and social variables: Age at time of interview, gender, cause of injury, time after injury and educational level (four levels, from primary school only to university).

Injury-related variables: The combination of both completeness and level of the injury was defined as 'impairment type'. Persons were grouped into four categories: complete tetraplegia (Frankel Grade A or B), incomplete tetraplegia (Frankel Grade C or D), complete paraplegia (Frankel A or B) and incomplete paraplegia (Frankel Grade C or D). ${ }^{16}$

Physical disabilities: These were measured by the 10item Barthel Index (BI) and divided into five groups (BI score $0-4$ very severely disabled, 5-9 severely disabled, 10-14 moderately disabled, 15-19 mildly disabled, 20 independent. ${ }^{17,18}$

Work-related variables: Pre-injury: occupation and physical intensity of work. Post injury: employment status, occupation and physical intensity of work, number of gainful working hours per week, net monthly family income level, sources of financial support, whether people thought to be capable of working, whether the persons returned to their pre-

Table 1 5-point scale to categorise the physical intensity of work

\begin{tabular}{|c|c|c|}
\hline Category & Description & Examples \\
\hline $\begin{array}{l}1=\text { Seden- } \\
\text { tary }\end{array}$ & $\begin{array}{l}\text { Mainly sedentary work, } \\
\text { moving little }\end{array}$ & $\begin{array}{l}\text { Secretary, } \\
\text { Bookkeeper, } \\
\text { Desk clerk }\end{array}$ \\
\hline $2=$ Light & $\begin{array}{c}\text { Moving, carrying light } \\
\text { weight }\end{array}$ & $\begin{array}{c}\text { Bookseller, } \\
\text { Teacher, } \\
\text { Inspector, } \\
\text { Community worker, }\end{array}$ \\
\hline $3=$ Moderate & $\begin{array}{l}\text { Moving and carrying } \\
\text { weight, climbing stairs }\end{array}$ & $\begin{array}{c}\text { Security guard, } \\
\text { Foreman, } \\
\text { Production manager }\end{array}$ \\
\hline $4=$ Heavy & $\begin{array}{l}\text { Climbing stairs, carrying } \\
\text { weight, moving heavy } \\
\text { objects }\end{array}$ & $\begin{array}{l}\text { Mechanic, } \\
\text { Nurse, } \\
\text { Roadbuilder }\end{array}$ \\
\hline $\begin{array}{l}5=\text { Strenu- } \\
\text { ous }\end{array}$ & $\begin{array}{l}\text { Performing heavy } \\
\text { manoeuvres in unnatural } \\
\text { posture }\end{array}$ & $\begin{array}{l}\text { Dance teacher, } \\
\text { Fireman, } \\
\text { Steel bender }\end{array}$ \\
\hline
\end{tabular}

injury employer and whether persons were vocational retrained.

The physical intensity of work was classified in a 5point scale, which was developed by an independent senior job analyst/consultant. An alphabetical list of jobs, without any additional information, was presented to the consultant who blindly classified jobs into this scale (Table 1).

\section{Statistical procedures}

All analyses were performed with SPSS for windows version 6.1. Chi-square tests were used to test bivariate correlations between job status and possible predictors. The independent predictive value of factors influencing employment after SCI was analysed with logistic regression analysis. A probability value of $P<0.05$ was considered statistically significant.

\section{Results}

Of 526 eligible people, 423 could be traced of whom 318 were willing to participate. Of these, 234 were gainfully employed pre-injury and their data were used for further analysis.

Table 2 presents the general characteristics of the study sample. In the study group the mean age was 40.0 years (SD 11.7). The majority were men. Impairment type varied from complete tetraplegia to incomplete paraplegia. Causes of SCI were traffic accidents $(36 \%)$, occupational accidents $(17 \%)$, sports accidents $(15 \%)$, SCI due to illness or treatment $(16 \%)$, falling $(9 \%)$ and other causes $(9 \%)$. Time after injury varied between 0.8 and 8.5 years (mean 4.5, SD 1.8). A minority completed primary school only $(13 \%)$. The remainder had a higher level of completed education. Forty-seven per cent of the sample was very severely, severely or moderately disabled.

Table 2 also shows the characteristics of the study sample divided into people with $(37 \%)$ and without $(63 \%)$ gainful employment after SCI. At time of interview only 87 people $(37 \%)$ were gainfully employed. Our results show that lower age $(P<0.01)$, male sex $(P<0.05)$, higher education $(P<0.001)$, lower intensity of work pre-injury $(P<0.01)$, retraining $(P<0.05)$ and higher Barthel Index $(P<0.01)$ were related with a higher rate of reemployment after SCI. In contrast, impairment type and time since injury were not related with higher reemployment rates.

In the group of people aged between 36 and 45 years, $53 \%$ were gainfully employed post SCI. In the group aged between 56 and 65 years, the number of people with a post-injury job declined considerably, perhaps as a result of early retirement as a personal choice. Men regained jobs more frequently than women $(40 \%$ versus $23 \%)$. Only $19 \%$ of the people with the lowest education (primary school) were employed post injury. In contrast, $59 \%$ of the highly 
Table 2 Characteristics of study sample $(n=234)$ and comparison of characteristics between groups working $(n=87)$ and not working $(n=147)$ post injury

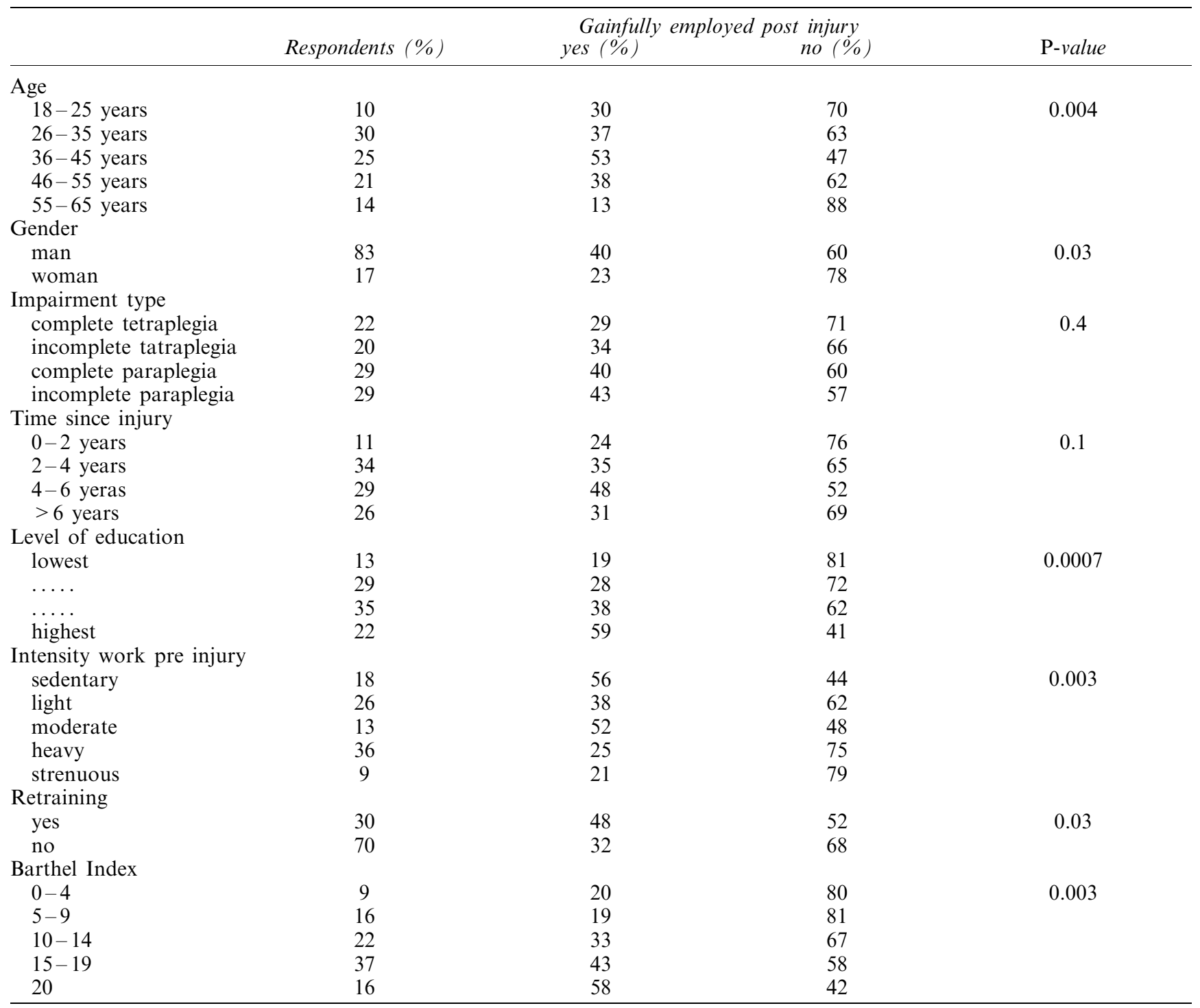

educated people (post secondary: university, college) regained a paid job. People with heavy and strenuous physical work pre-injury regained work in only $25 \%$, respectively, $21 \%$ of the cases, while in the three lighter categories more people became re-employed (56\%, 38\% and 52\%, respectively). After retraining, $48 \%$ of people regained a paid job versus only $33 \%$ without a retraining program. Fifty-eight per cent of the independent people (BI 20) regained a paid job against $20 \%(n=4)$ of the very severely disabled (BI $0-4)$. Two of these four very severely disabled people were running their own company (a garage/a factory), the other two had a part-time sedentary job.

While all people were gainfully employed pre-injury, only $37 \% \quad(n=87)$ were employed post-injury. Sixteen per cent $(n=14)$ of these employed people worked $1-$ $19 \mathrm{~h}$ per week, $44 \%(n=38)$ worked $20-37 \mathrm{~h}$ per week and $40 \%(n=35)$ had a full-time job (in the Netherlands a full time job is $38 \mathrm{~h}$ per week). Sixty-five per cent of those who returned to work returned to the same employer, of whom $50 \%$ returned to the same job. However, they frequently worked fewer hours per week. Out of the 147 people without a gainful job post-injury, 43\% $(n=63)$ judged themselves capable to work. Of all 234 people, 85\% had some sort of social benefit. Even people who had succeeded in regaining a job still had a supplementary social benefit: 93\% (13/ 14) of those working $1-19 \mathrm{~h}$ per week, $82 \%$ (31/38) of those working $20-37 \mathrm{~h}$ per week and $40 \%$ (14/35) of those who had a full-time job. Ninety-seven per cent of the people without a post-injury job had social benefit.

Having a paid job after injury was related to family income: a net family income level below 2000 guilders 
a month was earned by $47 \%(69 / 147)$ of those without a job against $14 \%(2 / 14)$ of those working $0-19 \mathrm{~h}$ per week, $11 \%(4 / 38)$ of those working $20-37 \mathrm{~h}$ per week and against $3 \%(1 / 35)$ of those having a full-time job. An income above 3500 guilders per week was earned by $13 \%(19 / 147)$ of people without a job against $44 \%$ $(15 / 34)$ of those who worked full-time at the time of the interview.

In Table 3 the physical intensity of the pre-injury occupations are compared with the post-injury occupations. Most people who were grouped in the heavy and strenuous physical categories pre-injury were unemployed $(74 \%$ respectively $79 \%)$ or had an (adapted) physically demanding occupation postinjury. Ten people had a rather physically demanding occupation post injury. All of them had a BI of 15 or more. Three of these ten people worked full-time and four ran their own company. Their workplace was probably sufficiently adapted; for example, one of them was a cattle breeder who had a wheelchair accessible tractor.

Thirty-six people found a physically lighter occupation post-injury and two found a more physically demanding job, while the remaining 49 stayed in the same category. Of the 49 people who stayed in the same category, $61 \%$ worked part time: $14 \%(n=7)$ worked $1-19 \mathrm{~h}$ per week and $47 \%(n=23)$ worked $20-37 \mathrm{~h}$ per week.

Table 4 shows the results of a logistic regression analysis testing possible predictors of return to work. The included variables were age (younger or older than 45 years), gender (man or woman), intensity of pre-injury work (light to moderate versus heavy and strenuous), Barthel index (more or less than 15) and educational level (high versus low) and retraining post-injury (yes or no). The results of the logistic regression analysis indicated that $69.7 \%$ was correctly predicted: $80.0 \%$ of the people who did not work post-injury and $52.3 \%$ of the people who restarted work was correctly predicted.

The chance of being employed post-injury was 2.5 times higher for people with a Barthel Index of more than $15,>3$ times higher for men and also $>3$ times higher for people with a pre-injury job requesting only a light to moderate physical intensity. The chance of working post-injury increased two times for highly educated people and for people who followed a retraining program. Age did not have significant predictive value.

\section{Discussion}

This study investigated a number of factors influencing the return to gainful employment after SCI in a large employed population. In our study, the re-employment rate after SCI was only $37 \%$, which is in the same range as found in other studies. ${ }^{3-13}$ However, since most other studies included also pre-injury unemployed, students and housekeepers in their samples, the re-employment rate was relatively low in our study. An extremely high number of those who returned to work returned to the same employer $(65 \%)$ and to the same job (33\%). Unexpected, was the percentage of $43 \%$ of the unemployed people who judged themselves capable to work.

The most important predictive factor for return to gainful employment that we found was a high score on the Barthel Index, which is concordant with previous results. $^{4-14}$ The second most important predictive factor was the physical intensity of the pre-injury occupation. Persons with less physically demanding occupations pre-injury were more likely to be employed post-injury. Only $14 \%$ of the post SCI gainfully employed had a physically demanding job, which is similar to previous results. ${ }^{15}$ This may be caused by difficulties in adapting the workplace or job in case of a physically demanding job. However, some people were very inventive in adapting their workplace. In addition, this may also be the result of a decreased personal motivation to choose a less

Table 4 Prediction of post injury employment $(n=234)$

\begin{tabular}{lcccc}
\hline Variable & Wald & $\mathrm{P}$ & Odds ratio & $95 \% \mathrm{Cl}$ \\
\hline Age & 2.04 & 0.1527 & 1.67 & $0.83,3.35$ \\
Gender & 8.52 & 0.0035 & 3.70 & $1.54,8.92$ \\
$\begin{array}{l}\text { Educational } \\
\quad \text { level }\end{array}$ & 4.98 & 0.0256 & 2.12 & $1.10,4.08$ \\
$\begin{array}{l}\text { Intensity } \\
\quad \text { occupation }\end{array}$ & 10.19 & 0.0014 & 3.16 & $1.56,6.39$ \\
$\quad$ pre injury & & & & \\
$\begin{array}{l}\text { Retraining } \\
\text { Barthel index }\end{array}$ & 4.70 & 0.0302 & 2.14 & $1.08,4.26$ \\
\hline
\end{tabular}

Table 3 Intensity of work pre and post injury $(n=234)$

\begin{tabular}{|c|c|c|c|c|c|c|c|}
\hline $\begin{array}{l}\text { Post injury/ } \\
\text { Pre injury }\end{array}$ & $\underset{(\%)}{\text { Unemployed }}$ & $\begin{array}{c}\text { Sedentary } \\
(\%)\end{array}$ & $\begin{array}{c}\text { Light } \\
(\%)\end{array}$ & $\begin{array}{c}\text { Moderate } \\
(\%)\end{array}$ & $\begin{array}{c}\text { Heavy } \\
(\%)\end{array}$ & $\begin{array}{c}\text { Strenuous } \\
(\%)\end{array}$ & $\begin{array}{l}\text { Total } \\
(\%)\end{array}$ \\
\hline Sedentary & $20(47)$ & $23(54)$ & & & & & 43 (18) \\
\hline Light & $38(62)$ & $9(15)$ & $13(21)$ & $1(2)$ & & & $61(26)$ \\
\hline Moderate & $15(48)$ & $6(19)$ & 4 (13) & $5(16)$ & $1(3)$ & & 31 (13) \\
\hline Heavy & $63(74)$ & $8(9)$ & $4(5)$ & 3 (4) & $7(8)$ & & $85(36)$ \\
\hline Strenuous & $11(79)$ & $1(7)$ & & & $1(7)$ & $1(7)$ & $14(6)$ \\
\hline Total & 147 (63) & $47(20)$ & $21(9)$ & $9(4)$ & $9(4)$ & $1(0)$ & $234(100)$ \\
\hline
\end{tabular}


physically demanding job. For example, people with a lower educational level may be less suitable for administrative work or who may not want to have a sedentary job. Levi et $a l^{19}$ found that SCI subjects were more often working with computers and less often working in (heavy) manual labour. People with occupations demanding the same level of physical intensity post-injury as it was pre-injury often worked part time. In this study being male was important to employment, but gender differences are highly dependent of cultural and social norms. As previously described education pre and post-injury were significant predictors. ${ }^{5-11,14}$ When controlling for other predictors, age was not related to employment.

In comparison with other countries, the Netherlands has a very well developed social security system. This way, people can receive an income when they are disabled, sick or for other reasons unfit to work. This financial compensation equals about $70 \%$ of their last earned salary. As a consequence, people who work full-time have a higher income than when they only rely on this form of social security, but working parttime is often not financially rewarding. Perhaps the existence of such a compensation form is one reason for the high number of people who remain vocationally inactive. In a Swedish study (Sweden also has a strongly developed social security system), over $70 \%$ of SCI subjects received sick-pension ${ }^{19}$ compared with $85.4 \%$ in this study. In both studies the majority of people who did not have a full time job had to rely on some sort of social benefit as their source of income and financial reserves were sparse. In contrast to the situation in the USA, in the Netherlands there are not

\section{References}

1 Ville I, Ravaud JF. Work values: a comparison of non-disabled persons with paraplegia. Disability and Rehabilitation 1998; 20(4): $127-137$.

2 Krause JS, Sternberg M, Lottes S, Maides J. Mortality after spinal cord injury: an 11-year prospective study. Arch Phys Med Rehabil 1997; 78: 815-821.

3 Trieschmann RB. In: Spinal Cord Injuries: psychological, social and vocational rehabilitation. 2 nd edn. Demos Publications: New York 1988.

4 Athanasou JA, Murphy GC. Employment rates for compensatable spinal injuries in Australia. International Journal of Rehabilitation Research 1993; 16: 151-156.

5 DeVivo MJ, Rutt RD, Stover SL, Fine RR. Employment after spinal cord injury. Arch Phys Med Rehabil 1987; 68: $494-498$.

6 McShane SL, Karp J. Employment following spinal cord injury: a covariance structure analysis. Rehabilitation Psychology 1993; 38: $27-40$.

7 Krause JS. Employment after spinal cord injury. Arch Phys Med Rehabil 1992; 73: 163 - 169.

8 Krause JS, Anson CA. Employment after spinal cord injury: relation to selected participant characteristics. Arch Phys Med Rehabil 1996; 77: 737-743.

9 Ville I, Ravaud JF. Work, non-work and consequent satisfaction after spinal cord injury. International Journal of Rehabilitation Research 1996; 19: $241-252$.

10 Murphy $\mathrm{G}$ et al. Labour force participation and employment among a sample of Australian patients with a spinal cord injury. Spinal Cord 1997; 35: 238-244. many claims after an accident which causes SCI and the amounts of money claimed will never be sufficient to eliminate the need to work (in part because of the aforementioned financial compensation).

Several limitations concern this study. First of all, this is a retrospective study. Secondly, little information of the actual job content and about pre-injury work was available so that our categorisation is necessarily rough and some jobs might have been misclassified. Thirdly, the scale to classify jobs did not exist and had to be developed and therefore comparisons with previous studies could not be made. Availability of suitable jobs and transportation as well as motivation and attitude to work are potentially important predictors of regaining employment but were not incorporated in this study.

In conclusion, most people do not return to work after SCI, not even in a physically less demanding job. Return to gainful employment was most likely in mildly or not disabled, highly educated men whose pre-injury job only demanded light to moderate physical capacities and who followed a retraining program. The percentage of unemployed thought to be capable of working is remarkably high. Our impression is that in many cases people are only ready to think of regaining work when they are at a stable level of functioning and their domestic situation is settled. At that time, they are discharged from the rehabilitation centre so less help with job specific functional training is available and intensive inpatient reeducation is less attractive. Long-term support in finding a job is very important in this group of patients.

11 Krause JS, Sternberg M, Maides J, Lottes S. Employment after spinal cord injury: differences related to geographic region, gender, and race. Arch Phys Med Rehabil 1998; 79: 615-624.

12 DeVivo MJ, Fine PR. Employment status of spinal cord injured patients 3 years after injury. Arch Phys Med Rehabil 1982; 63: $200-203$.

13 Crewe NM, Krause JS. An eleven-year follow up of adjustment to spinal cord injury. Rehabilitation Psychology 1990; 35: $205-$ 210.

14 Wayne GA, Fuhrer MJ, Rossi CD. Vocational development following severe spinal cord injury: a longitudinal study. Arch Phys Med Rehabil 1987; 68: 854-857.

15 Castle R. An investigation into the employment and occupation of patients with a spinal cord injury. Paraplegia 1994; 32: 182 187.

16 Frankel HL, Hancock DO, Hyslop G et al. The value of postural reduction in the initial management of closed injuires of the spine with paraplegia and tetraplegia. Part 1. Paraplegia 1969; 7: 179192.

17 Colin C, Wade DT, Davies S, Horne V. The Barthel ADL index: a reliability study. Int Disabil Stud 1988; 10: 61-63.

18 Post MWM, Asbeck FWA van, Dijk AJ van, Schrijvers AJP. Een Nederlandse interview-versie van de Barthel Index onderzocht bij dwarslaesiepatiëntgen. Ned Tijdschr Geneeskd 1995; 139: $1376-1380$.

19 Levi R, Hultling C, Seiger A. The Stockholm spinal cord injury: 4. Psychosocial and financial issues of the Swedish annual levelof-living survey in SCI subjects and controls. Paraplegia 1996; 34: $152-157$. 